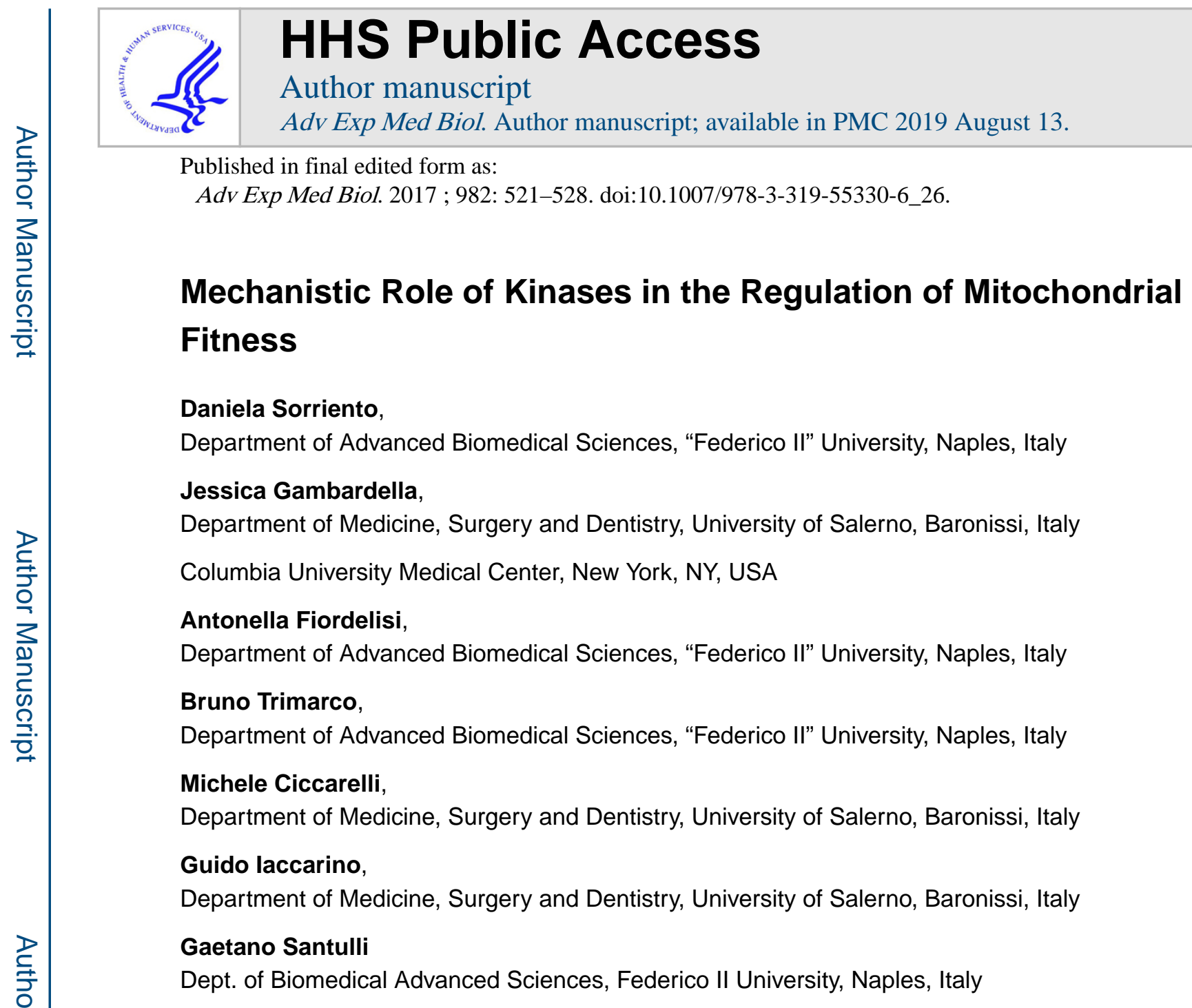

Abstract

Mounting evidence indicates that mitochondria contain multiple phosphorylation substrates and that protein kinases translocate into mitochondria, suggesting that protein phosphorylation in this organelle could be fundamental for the regulation of its own function. Here we examine the mechanistic role of cellular kinases in the fine regulation of key mitochondrial activities, including mitochondrial quality control, fission/fusion processes, metabolism, and mitophagy.

\title{
Mitochondrial Respiration
}

Mitochondria are cytoplasmic organelles that are involved in oxidative energy metabolism, producing the most of our cellular energy by oxidative phosphorylation [1,2], through the metabolization of nutrients and production of ATP. Mitochondrial ATP production relies on the electron transport chain (ETC), composed of respiratory chain complexes I-IV. 


\section{The Regulation of Proteins in the ETC}

SRC family kinases (SFKs) are the most involved in tyrosine phosphorylation of mitochondrial proteins to regulate mitochondrial respiration. Src kinases affect the enzymatic activities of complexes I, III-V; importantly, SRC phosphorylates different substrates in the ETC (Table 26.1). Indeed, Src is present inside mitochondria where it phosphorylates the subunit II of cytochrome c oxidase [3], increasing the enzymatic activity of complex IV. Moreover, adenine nucleotide translocase 1 (ANT1), which is able to transport ADP from cytosol within mitochondria in exchange of ATP, is known to be phosphorylated on $\mathrm{Tyr}^{190}$ and $\mathrm{Tyr}^{194}$ by c-Src kinase [4-6].

Src is also known to phosphorylate NDUFV2 (NADH dehydrogenase [ubiquinone] flavoprotein 2) of complex I at Tyr ${ }^{193}$, and SDHA (succinate dehydrogenase A) of complex II at $\operatorname{Tyr}^{215}$ [7]. NDUFV2 phosphorylation is required for NADH dehydrogenase activity, affecting respiration activity and cellular ATP content, while SDHA phosphorylation has no effect on enzyme activity, but affects reactive oxygen species production. Furthermore, the tyrosine protein kinase Fgr phosphorylates flavoprotein of succinate dehydrogenase at $\mathrm{Tyr}^{535}$ and $\mathrm{Tyr}^{596}$ and aconitase at $\mathrm{Tyr}^{71}, \mathrm{Tyr}^{544}$, and $\operatorname{Tyr}^{665}[8,9]$.

\section{Mitochondrial Biogenesis}

Mitochondrial biogenesis can be defined as the growth and division of pre-existing mitochondria leading to a variation in number, size, and mass. It is dependent on different signaling cascades and transcriptional complexes that promote the formation and assembly of mitochondria.

\section{The Regulation of PCG1a}

The peroxisome proliferator-activated receptor $\gamma$ coactivator 1 (PGC1) family of transcriptional coactivators has recently emerged as central regulator of metabolism being a positive modulator of mitochondrial biogenesis and respiration [10]. PGC1a is a cotranscriptional regulation factor that induces mitochondrial biogenesis by activating different transcription factors, including NRF-1 and NRF-2. These latters on turn activate Tfam to increase replication of mtDNA and to induce the transcription of key mitochondrial enzymes [11]. AMPK, p38 MAPK, and GSK3p are the best-characterized protein kinases known to target PGC1a. It has been shown that PGC1a is increased in response to activation of AMPK and is reduced in both AMPK null [12] and dominant negative mice [13]. Indeed, AMPK directly phosphorylates PGC1a on Thr177 and Ser538 [14] thereby enhancing its co-transcriptional activity and consequently mitochondrial gene expression. p38 MAPK phosphorylates PGCla at $\mathrm{Thr}^{262}, \mathrm{Ser}^{265}$, and $\mathrm{Thr}^{298}$ in response to cytokine stimulation in muscle cells [15]. Moreover, it enhances the activity of PGC1a by increasing its stability and by disrupting the inactivating interaction between PGC1a and the co-repressor p160MBP in myoblasts [16]. Finally, PGC-1a is also phosphorylated by glycogen synthase kinase $3 \beta$ (GSK3 $\beta$ ), which inhibits PGC1a by enhancing its proteasomal degradation in the nucleus during oxidative stress [17]. 


\section{Mitochondrial Quality Control}

Mitochondria have an important role in the regulation of cell survival, cell death and metabolic homeostasis. They continuously fuse or divide to maintain their functions and damaged mitochondria after fission are removed through mitophagy. Thus, several mechanisms are involved in the regulation of mitochondrial quality control including mitochondrial fission and fusion [18], Parkin-dependent pathways [19] and degradation of damaged mitochondria by lysosomes [20] and autophagosomes [21].

\section{The Regulation of Mitochondrial Fission}

Mitochondria fission and fusion are mainly mediated by highly conserved guano-sine triphosphatases (GTPases) [22, 23]. Among them, dynamin-related protein 1 (DRP1) is the GTPase that regulates mitochondrial fission [24, 25]. It is a cytosolic protein that once activated translocates to the outer mitochondrial membrane where multimerizes in order to create a ring-like structure that constricts and divides the organelle [26, 27]. Drp1 activity is mainly regulated through phosphorylation in different sites by several protein kinases (Table 26.2). However, data on the effects of DRP1 phosphorylation are rather puzzling since different kinases phosphorylates the same site in DRP1 resulting in opposing effects, as described below.

PKA has a key role in the regulation of DRP1 activity by preventing its translocation to the mitochondria and inhibiting the process of mitochondrial fission. Indeed, Cribbs \& Strack demonstrated that PKA phosphorylates Drp1 at Ser ${ }^{656}$ and this attenuates the GTPase activity of Drp1 promoting cell survival [28]. Chang \& Blackstone discovered that PKA phosphorylates DRP1 also at $\operatorname{Ser}^{637}$ inhibiting its GTPase activity [29]. Accordingly, the phospho-mimetic substitution Ser637Asp blocks mitochondrial fission and apoptotic cell death [29]. Thus, PKA exerts an inhibitory effect on DRP1 activation by phosphorylation of both $\operatorname{Ser}^{656}$ and $\mathrm{Ser}^{637}$, even if no data are available to understand whether phosphorylation at these sites could have different physiological implications. On the contrary, phosphorylation of $\mathrm{Ser}^{637}$, which is inhibitory in PKA signaling, induced mitochondrial fission when is due to $\mathrm{Ca}^{2}+/$ calmodulin-dependent protein kinase Ia (CaMKIa) [30]. Similarly, phosphorylation of DRP1 at $\mathrm{Ser}^{616}$ by ERK2 activates DRP1 and promotes mitochondrial fission [31], whereas phosphorylation at the same residue by CDK5 exerts opposite effects [32]. Thus, the effects of DRP1 phosphorylation on mitochondrial fission depend on both the type of kinase and the specific phosphorylated residues. However, further studies are needed to clarify such effects.

\section{Regulation of Mitochondrial Fusion}

Mitofusins (MFNs) 1 and 2 are a class of conserved GTPases of the mitochondrial outer membrane that are essential for mitochondrial fusion and consequently to maintain normal mitochondrial morphology. MFNs are essential for normal cardiac function. Indeed, the combined deletion of MFN1 and MFN2 in murine hearts induces mitochondrial and cardiomyocyte dysfunction which rapidly leads to progressive and lethal dilated cardiomyopathy. MFN1 and 2 can be phosphorylated and such phosphorylation affects their ability to modulate mitochondrial fusion (Table 26.3). 
Indeed, MFN2 was found to be phosphorylated by PINK1 at Thr ${ }^{111}$ and $\mathrm{S}^{442}$ to become a mitochondrial receptor for Parkin and eventually promote mitophagy. Moreover, MFN2 can be also phosphorylated by JNK at Ser27 causing its degradation through the ubiquitinproteasome pathway which in turn affects both mitochondrial dynamics and apoptosis [33]. Also MFN1 can be phosphorylated at $\mathrm{Th}^{562}$ by ERK to modulate apoptotic responses [34]. Indeed, this inhibitory phosphorylation of MFN1 induces its association with BAK facilitating its oligomerization and inducing cytochrome $c$ release and cell death [34].

\section{Parkin-Dependent Mechanisms}

PINK1 is a kinase associated with mitochondria: the loss of this kinase expression causes mitochondrial dysfunction and mitophagy [35-37]. Parkin is an E3 ubiquitin ligase suggested to be downstream of PINK1 to regulate the removal of damaged mitochondria. Indeed, PINK1 is activated by mitochondria membrane potential depolarization and is imported into mitochondria to activate Parkin [38-41]. This latter causes proteasomal degradation of outer mitochondrial membrane proteins $[42,43]$ and selective autophagy of damaged mitochondria [44], suggesting that PINK1 and Parkin mediate a mitochondrial quality control pathway. The removal of damaged mitochondria was thought to be mainly attributable to the activation of PINK1-Parkin-Ubiquitin cascade: PINK1 directly phosphorylates Parkin at Ser ${ }^{65}$ which on turn activates Ubiquitin [45]. Actually, recent findings changed this view: PINK1 has been shown to recruit Parkin to mitochondria also in presence of mutation of $\mathrm{Ser}^{65}$ to Alanine suggesting the ability of PINK1 to regulate Parkin in a phosphorylation independent manner. Moreover, PINK1 directly phosphorylates Ubiquitin at Ser ${ }^{65}$ which on turn activates Parkin [46]. Thus, PINK1 phosphorylates at Ser ${ }^{65}$ both Parkin and Ubiquitin to induce the full activation of Parkin, as summarized in Fig. 26.1.

\section{Acknowledgements}

Dr. Gaetano Santulli, M.D., Ph.D. is supported by the National Institutes of Health (NIH, Grant NIDDK107895).

\section{References}

1. Chance B, Sies H, Boveris A. Hydroperoxide metabolism in mammalian organs. Physiol Rev. 1979;59:527-605. [PubMed: 37532]

2. Sorriento D, Ciccarelli M, Santulli G, Illario M, Trimarco B, Iaccarino G. Trafficking GRK2: cellular and metabolic consequences of GRK2 subcellular localization. Transl Med UniSa. 2014;10:3-7. [PubMed: 25147759]

3. Miyazaki T, Neff L, Tanaka S, Horne WC, Baron R. Regulation of cytochrome c oxidase activity by c-Src in osteoclasts. J Cell Biol. 2003;160:709-18. [PubMed: 12615910]

4. Lewandrowski U, Sickmann A, Cesaro L, Brunati AM, Toninello A, Salvi M. Identification of new tyrosine phosphorylated proteins in rat brain mitochondria. FEBS Lett. 2008;582:1104-10. [PubMed: 18331841]

5. Feng J, Zhu M, Schaub MC, Gehrig P, Roschitzki B, Lucchinetti E, Zaugg M. Phosphoproteome analysis of isoflurane-protected heart mitochondria: phosphorylation of adenine nucleotide translocator-1 on Tyr194 regulates mitochondrial function. Cardiovasc Res. 2008;80:20-9. [PubMed: 18558627]

6. Feng J, Lucchinetti E, Enkavi G, Wang Y, Gehrig P, Roschitzki B, Schaub MC, Tajkhorshid E, Zaugg K, Zaugg M. Tyrosine phosphorylation by Src within the cavity of the adenine nucleotide translocase 1 regulates ADP/ATP exchange in mitochondria. Am J Phys Cell Phys. 2010;298:C7408. 
7. Ogura M, Yamaki J, Homma MK, Homma Y. Mitochondrial c-Src regulates cell survival through phosphorylation of respiratory chain components. Biochem J. 2012;447:281-9. [PubMed: 22823520]

8. Salvi M, Morrice NA, Brunati AM, Toninello A. Identification of the flavoprotein of succinate dehydrogenase and aconitase as in vitro mitochondrial substrates of Fgr tyrosine kinase. FEBS Lett. 2007;581:5579-85. [PubMed: 17997986]

9. Thomson M Evidence of undiscovered cell regulatory mechanisms: phosphoproteins and protein kinases in mitochondria. Cellular Mol Life Sci: CMLS. 2002;59:213-9. [PubMed: 11915939]

10. Handschin C, Spiegelman BM. Peroxisome proliferator-activated receptor gamma coactivator 1 coactivators, energy homeostasis, and metabolism. Endocr Rev. 2006;27:728-35. [PubMed: 17018837]

11. Virbasius JV, Scarpulla RC. Activation of the human mitochondrial transcription factor A gene by nuclear respiratory factors: a potential regulatory link between nuclear and mitochondrial gene expression in organelle biogenesis. Proc Natl Acad Sci U S A. 1994;91:1309-13. [PubMed: 8108407]

12. Iglesias MA, Furler SM, Cooney GJ, Kraegen EW, Ye JM. AMP-activated protein kinase activation by AICAR increases both muscle fatty acid and glucose uptake in white muscle of insulin-resistant rats in vivo. Diabetes. 2004;53:1649-54. [PubMed: 15220186]

13. Watt MJ, Steinberg GR, Chan S, Garnham A, Kemp BE, Febbraio MA. Beta-adrenergic stimulation of skeletal muscle HSL can be overridden by AMPK signaling. FASEB J: Off Publ Feder Am Soc Exp Biol. 2004;18:1445-6.

14. Jager S, Handschin C, St-Pierre J, Spiegelman BM. AMP-activated protein kinase (AMPK) action in skeletal muscle via direct phosphorylation of PGC-1alpha. Proc Natl Acad Sci U S A. 2007;104:12017-22. [PubMed: 17609368]

15. Puigserver P, Rhee J, Lin J, Wu Z, Yoon JC, Zhang CY, Krauss S, Mootha VK, Lowell BB, Spiegelman BM. Cytokine stimulation of energy expenditure through p38 MAP kinase activation of PPARgamma coactivator-1. Mol Cell. 2001;8:971-82. [PubMed: 11741533]

16. Fan M, Rhee J, St-Pierre J, Handschin C, Puigserver P, Lin J, Jaeger S, Erdjument-Bromage H, Tempst P, Spiegelman BM. Suppression of mitochondrial respiration through recruitment of p160 myb binding protein to PGC-1alpha: modulation by p38 MAPK. Genes Dev. 2004;18:278-89. [PubMed: 14744933]

17. Anderson RM, Barger JL, Edwards MG, Braun KH, O’Connor CE, Prolla TA, Weindruch R. Dynamic regulation of PGC-1 alpha localization and turnover implicates mitochondrial adaptation in calorie restriction and the stress response. Aging Cell. 2008;7:101-11. [PubMed: 18031569]

18. van der Bliek AM, Shen Q, Kawajiri S. Mechanisms of mitochondrial fission and fusion. Cold Spring Harb Perspect Biol. 2013;5.

19. Ding WX, Yin XM. Mitophagy: mechanisms, pathophysiological roles, and analysis. Biol Chem. 2012;393:547-64. [PubMed: 22944659]

20. Soubannier V, Rippstein P, Kaufman BA, Shoubridge EA, McBride HM. Reconstitution of mitochondria derived vesicle formation demonstrates selective enrichment of oxidized cargo. PLoS ONE. 2012;7:e52830. [PubMed: 23300790]

21. Youle RJ, Narendra DP. Mechanisms of mitophagy. Nat Rev Mol Cell Biol. 2011;12:9-14. [PubMed: 21179058]

22. Youle RJ, van der Bliek AM. Mitochondrial fission, fusion, and stress. Science. 2012;337: 1062-5. [PubMed: 22936770]

23. Ishihara N, Otera H, Oka T, Mihara K. Regulation and physiologic functions of GTPases in mitochondrial fusion and fission in mammals. Antioxid Redox Signal. 2013;19:389-99. [PubMed: 22871170]

24. Cribbs JT, Strack S. Functional characterization of phosphorylation sites in dynamin-related protein 1. Methods Enzymol. 2009;457:231-53. [PubMed: 19426871]

25. Chen H, Detmer SA, Ewald AJ, Griffin EE, Fraser SE, Chan DC. Mitofusins Mfn1 and Mfn2 coordinately regulate mitochondrial fusion and are essential for embryonic development. J Cell Biol. 2003;160:189-200. [PubMed: 12527753] 
26. Zhu PP, Patterson A, Stadler J, Seeburg DP, Sheng M, Blackstone C. Intra- and intermolecular domain interactions of the C-terminal GTPase effector domain of the multimeric dynamin-like GTPase Drp1. J Biol Chem. 2004;279:35967-74. [PubMed: 15208300]

27. Lee YJ, Jeong SY, Karbowski M, Smith CL, Youle RJ. Roles of the mammalian mitochondrial fission and fusion mediators Fis1, Drp1, and Opa1 in apoptosis. Mol Biol Cell. 2004;15:5001-11. [PubMed: 15356267]

28. Cribbs JT, Strack S. Reversible phosphorylation of Drp1 by cyclic AMP-dependent protein kinase and calcineurin regulates mitochondrial fission and cell death. EMBO Rep. 2007;8:939-44. [PubMed: 17721437]

29. Chang CR, Blackstone C. Cyclic AMP-dependent protein kinase phosphorylation of Drp1 regulates its GTPase activity and mitochondrial morphology. J Biol Chem. 2007;282: 21583-7. [PubMed: 17553808]

30. Han XJ, Lu YF, Li SA, Kaitsuka T, Sato Y, Tomizawa K, Nairn AC, Takei K, Matsui H, Matsushita M. CaM kinase I alpha-induced phosphorylation of Drp1 regulates mitochondrial morphology. J Cell Biol. 2008;182:573-85. [PubMed: 18695047]

31. Kashatus JA, Nascimento A, Myers LJ, Sher A, Byrne FL, Hoehn KL, Counter CM, Kashatus DF. Erk2 phosphorylation of Drp1 promotes mitochondrial fission and MAPK-driven tumor growth. Mol Cell. 2015;57:537-51. [PubMed: 25658205]

32. Cho B, Cho HM, Kim HJ, Jeong J, Park SK, Hwang EM, Park JY, Kim WR, Kim H, Sun W. CDK5-dependent inhibitory phosphorylation of Drp1 during neuronal maturation. Exp Mol Med. 2014;46:e105. [PubMed: 25012575]

33. Leboucher GP, Tsai YC, Yang M, Shaw KC, Zhou M, Veenstra TD, Glickman MH, Weissman AM. Stress-induced phosphorylation and proteasomal degradation of mitofusin 2 facilitates mitochondrial fragmentation and apoptosis. Mol Cell. 2012;47:547-57. [PubMed: 22748923]

34. Pyakurel A, Savoia C, Hess D, Scorrano L. Extracellular regulated kinase phosphorylates mitofusin 1 to control mitochondrial morphology and apoptosis. Mol Cell. 2015;58:244-54. [PubMed: 25801171]

35. Geisler S, Holmstrom KM, Skujat D, Fiesel FC, Rothfuss OC, Kahle PJ, Springer W. PINK1/ Parkin-mediated mitophagy is dependent on VDAC1 and p62/SQSTM1. Nat Cell Biol. 2010;12:119-31. [PubMed: 20098416]

36. Narendra DP, Jin SM, Tanaka A, Suen DF, Gautier CA, Shen J, Cookson MR, Youle RJ. PINK1 is selectively stabilized on impaired mitochondria to activate Parkin. PLoS Biol. 2010;8:e1000298. [PubMed: 20126261]

37. Matsuda N, Sato S, Shiba K, Okatsu K, Saisho K, Gautier CA, Sou YS, Saiki S, Kawajiri S, Sato F, Kimura M, Komatsu M, Hattori N, Tanaka K. PINK1 stabilized by mitochondrial depolarization recruits Parkin to damaged mitochondria and activates latent Parkin for mitophagy. J Cell Biol. 2010;189:211-21. [PubMed: 20404107]

38. Lin W, Kang UJ. Characterization of PINK1 processing, stability, and subcellular localization. J Neurochem. 2008;106:464-74. [PubMed: 18397367]

39. Jin SM, Lazarou M, Wang C, Kane LA, Narendra DP, Youle RJ. Mitochondrial membrane potential regulates PINK1 import and proteolytic destabilization by PARL. J Cell Biol. 2010;191:933-42. [PubMed: 21115803]

40. Deas E, Wood NW, Plun-Favreau H. Mitophagy and Parkinson's disease: the PINK1-parkin Link. Biochim Biophys Acta. 1813;2011:623-33.

41. Yamano K, Youle RJ. PINK1 is degraded through the N-end rule pathway. Autophagy. 2013;9:1758-69. [PubMed: 24121706]

42. Tanaka K, Matsuda N, Okatsu K. Mechanisms underling the cause of Parkinson's disease: the functions of Parkin/PINK1. Rinsho Shinkeigaku = Clin Neurol. 2010;50:867.

43. Yoshii SR, Kishi C, Ishihara N, Mizushima N. Parkin mediates proteasome-dependent protein degradation and rupture of the outer mitochondrial membrane. J Biol Chem. 2011; 286:19630-40. [PubMed: 21454557]

44. Narendra D, Tanaka A, Suen DF, Youle RJ. Parkin is recruited selectively to impaired mitochondria and promotes their autophagy. J Cell Biol. 2008;183:795-803. [PubMed: 19029340] 
45. Kondapalli C, Kazlauskaite A, Zhang N, Woodroof HI, Campbell DG, Gourlay R, Burchell L, Walden H, Macartney TJ, Deak M, Knebel A, Alessi DR, Muqit MM. PINK1 is activated by mitochondrial membrane potential depolarization and stimulates Parkin E3 ligase activity by phosphorylating Serine 65. Open Biol. 2012;2:120080. [PubMed: 22724072]

46. Kane LA, Lazarou M, Fogel AI, Li Y, Yamano K, Sarraf SA, Banerjee S, Youle RJ. PINK1 phosphorylates ubiquitin to activate Parkin E3 ubiquitin ligase activity. J Cell Biol. 2014;205:14353. [PubMed: 24751536] 


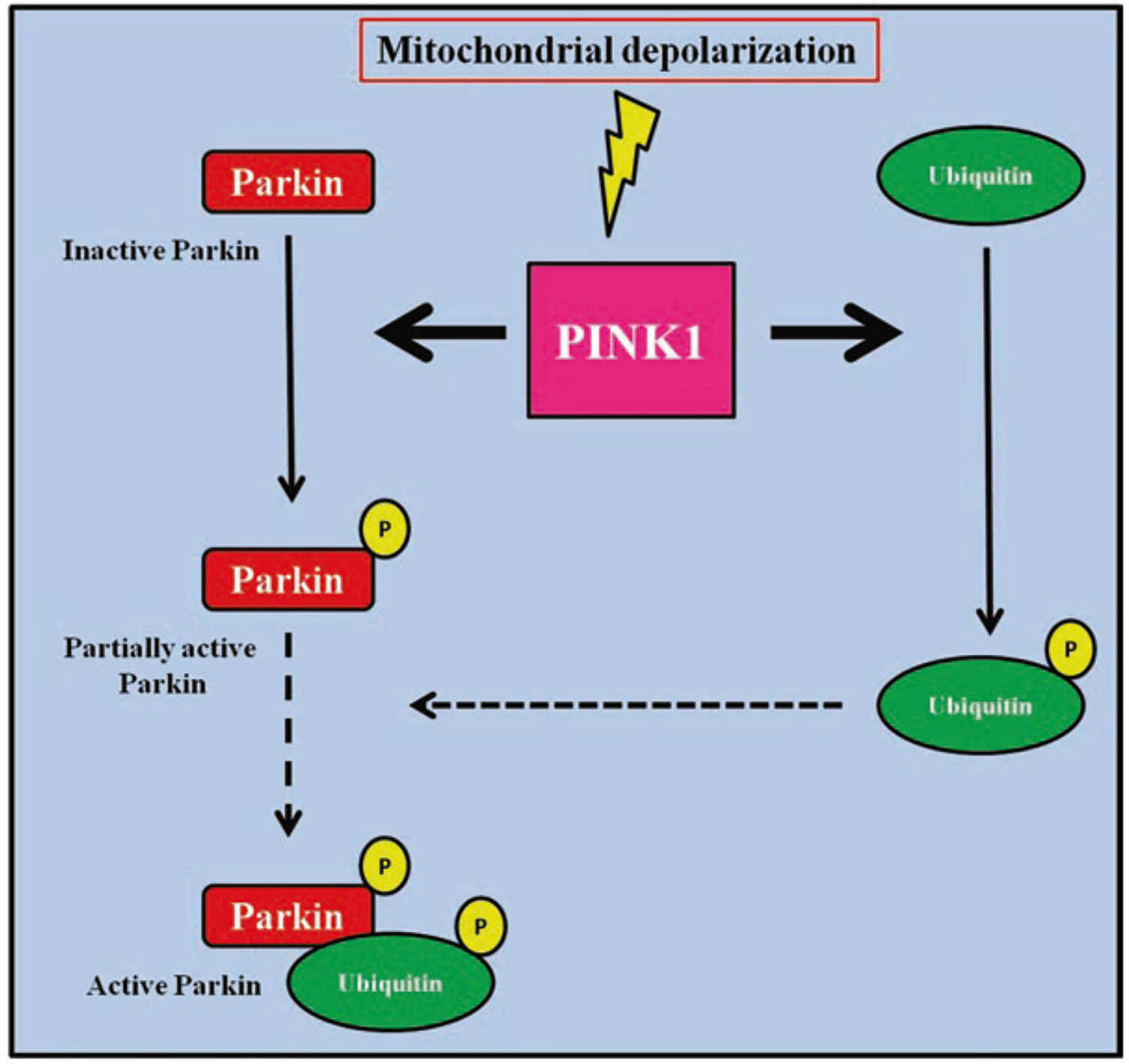

Fig. 26.1.

The full activation of Parkin is dependent on PINKl-mediated phosphorylation of both Parkin and ubiquitin at $\mathrm{Ser}^{65}$ 
Table 26.1

Substrates of SRC in the ETC e the effects of substrate phosphorylation

\begin{tabular}{l|l|l}
\hline SRC substrates & Phosphorylation sites & Effect \\
\hline ANT1 & $\operatorname{Tyr}^{190}$ and $\mathrm{Tyr}^{194}$ & Protection of cardiac mitochondria against ischemic-reperfusion injury \\
\hline Cytochrome c oxidase & unknown & Increase of the enzymatic activity of complex IV \\
\hline NDUFV2 & $\operatorname{Tyr}^{193}$ & Increase of NADH dehydrogenase activity \\
\hline SDHA & $\operatorname{Tyr}^{215}$ & Regulation of reactive oxygen species production \\
\hline
\end{tabular}


Table 26.2

Protein kinases that phosphorylate DRP1 and their effects on DRP1 activation

\begin{tabular}{l|l|l}
\hline Protein kinases & DRP1 phosphorylation sites & Effect on DRP1 \\
\hline \multirow{2}{*}{ PKA } & $\operatorname{Ser}^{656}$ & Inhibition \\
\cline { 2 - 3 } & $\operatorname{Ser}^{637}$ & Inhibition \\
\hline CaMK1a & $\operatorname{Ser}^{637}$ & Activation \\
\hline ERK & $\operatorname{Ser}^{616}$ & Activation \\
\hline CDK & $\operatorname{Ser}^{616}$ & Inhibition \\
\hline
\end{tabular}


Table 26.3

Mitofusins phosphorylation sites and effects of phosphorylation on mitophagy

\begin{tabular}{l|l|l}
\hline Protein kinases & MFN phosphorylation sites & Effect on mitophagy \\
\hline PINK1 & $\mathrm{T}^{111}$ of MFN2 & Activation \\
\hline PINK1 & $\mathrm{S}^{442}$ of MFN2 & Activation \\
\hline JNK & $\mathrm{Ser}^{27}$ of MFN2 & Inhibition \\
\hline ERK & $\mathrm{T}^{562}$ of MFN1 & Inhibition \\
\hline
\end{tabular}

